\title{
ALTA DIRECCIÓN PÚBLICA LATINOAMERICANA: MARCHAS Y CONTRAMARCHAS
}

\author{
Mercedes Iacoviello \\ mercedesiacoviello @gmail.com \\ Mercedes Llano \\ CONICET, Argentina \\ Universidad Nacional de Cuyo, Argentina \\ mechidd@yahoo.com.ar \\ Conrado Ramos \\ Universidad de la República, Uruguay \\ ramoslarraburu@gmail.com
}

\section{RESUMEN}

En América Latina son escasos los estudios que han abordado sistemáticamente los procesos de institucionalización de sistemas de alta dirección pública. Este artículo presenta un análisis actualizado de la situación de cuatro experiencias latinoamericanas (Argentina, Chile, México y Perú). Dada la inestabilidad de las políticas públicas en la región, resulta oportuno revisar dichas experiencias, para identificar posibles condicionantes y eventuales desafíos de la profesionalización de los altos directivos en la región. En particular, se exploran el grado de institucionalización del sistema de partidos, y los poderes constitucionales y partidarios del Presidente como posibles condicionantes estructurales de los itinerarios de reforma. Se concluye que estos determinantes institucionales por sí solos son insatisfactorios para explicar el derrotero de los cambios administrativos analizados, y que es necesario incorporar otras variables explicativas vinculadas a factores de agencia y culturas administrativas.

Palabras clave: Alta dirección pública, Servicio civil, Reformas administrativas, América Latina. 


\title{
LATIN AMERICAN SENIOR EXECUTIVE SERVICE: ADVANCES AND SETBACKS
}

\begin{abstract}
In Latin America there are scant studies that systematically deal with the processes of institutionalization of systems of senior executive service. This article presents an updated analysis of the situation in four Latin American countries (Argentina, Chile, Mexico and Peru). Given the instability of public policies in the region, it is appropriate to review these experiences to identify possible determinants and possible challenges of the professionalization of senior executives in the region. In particular, this study explores the degree of institutionalization of the party system, and the constitutional power and party power of the President as possible structural determinants of reform agendas. It is concluded that these institutional determinants alone are an unsatisfactory explanation of the course of the administrative changes analyzed, and that it is necessary to incorporate other explanatory variables linked to factors of agency and administrative culture.
\end{abstract}

Keywords: Senior executive service, Civil service, Administrative reforms, Latin America. 


\section{INTRODUCCIÓN}

El desarrollo de competencias directivas es considerado un factor crítico para mejorar el desempeño de la administración pública y los procesos de modernización (Kuperus y Rode 2008). Sin embargo, la profesionalización de los altos ejecutivos no ha logrado ocupar un lugar preeminente en la mayoría de las agendas de los gobiernos de América Latina, donde la confianza política sigue siendo el criterio predominante para la provisión de puestos jerárquicos (Cortázar Velarde, Fuenzalida y Lafuente 2016). Solo algunos países de la región impulsaron herramientas para consolidar en la burocracia pública un espacio específico con capacidades de dirección. El estudio de tales experiencias puede arrojar luz sobre las características, dinámicas y condicionantes de los procesos de modernización de las franjas ejecutivas en Latinoamérica.

Por ello, el presente artículo tiene por objeto abordar sistemáticamente las trayectorias de institucionalización de los Sistemas de Alta Dirección Pública, y sus limitantes, en un grupo de democracias latinoamericanas. Se toma como base un análisis comparativo entre distintos casos regionales que encararon reformas a nivel directivo realizado en el 2011 por Iacoviello, Llano y Strazza. Dada la inestabilidad de las políticas públicas en América Latina, se busca revisar dichas experiencias, para identificar las marchas y contramarchas y explorar las variables institucionales que operan como condicionantes de la profesionalización de las franjas gerenciales en nuestras latitudes.

El análisis se focaliza en los procesos de institucionalización de los Sistemas de Alta Dirección Pública implementados en Perú (Cuerpo de Gerentes Públicos, 2008), Argentina (Administradores Gubernamentales, 1984, y Funciones Ejecutivas, 1991), Chile (Sistema de Alta Dirección Pública, 2003) y México (Servicio Profesional de Carrera, 2003), a través de los cuales se ha intentado liderar las reformas administrativas y limitar la intromisión política en el aparato administrativo.

Sobre la base de los casos indagados, se propone realizar una aproximación exploratoria a los elementos que podrían viabilizar u obstaculizar la implantación de las reformas administrativas a nivel gerencial. Se ha señalado que los sistemas de alta dirección pública en los países en desarrollo varían de acuerdo a las tradiciones administrativas, factores sociales e institucionales y niveles de reforma (Halligan 2003), pero son escasos los estudios que han analizado sistemáticamente los condicionantes que inciden en la modernización gerencial (no así en el conjunto del servicio 
civil) en América Latina ${ }^{1}$. Este trabajo procura avanzar en esa dirección a través de un acercamiento a los componentes del entramado políticoinstitucional que podrían estar influyendo en la emergencia y consolidación de sistemas de directivos senior en la región. Para ello, se bosqueja un modelo piloto de cambio institucional aplicable a reformas directivas y se lo contrasta empíricamente a partir de la información recopilada de cada uno de los casos escogidos.

El artículo se estructura en cinco secciones. En el segundo apartado se describen las principales características, la dinámica y el alcance de las reformas impulsadas a nivel de las franjas ejecutivas en los cuatro casos seleccionados, para luego analizar comparativamente los itinerarios de modernización. A continuación, se indaga sobre la relación entre el sistema político y el desarrollo del espacio directivo estatal a la luz de un esquema explicativo de cambio administrativo que busca identificar los factores político-institucionales asociados al grado de implantación de los sistemas de alta gerencia pública. Finalmente, se presentan algunos comentarios.

\section{ANALIZANDO ALGUNAS EXPERENCIAS DE REFORMA DE LOS SISTEMAS DE ALTA DIRECCIÓN PÚBLICA EN AMÉRICA LATINA}

El modo convencional de good governance en la literatura académica de los países desarrollados incluye la constitución de un servicio civil profesional reclutado por mérito. En términos de Hood y Lodge (2006) esto significa que los agentes estatales son serial loyalists, siendo capaces de servir a cualquier master político con igual dedicación y entusiasmo. Los servidores públicos serán recompensados por su lealtad, con salarios dignos y cierta estabilidad en el empleo. Esto supuestamente produce una governance despolitizada, competente, responsable y accountable.

En esta idea es central el concepto de acuerdo entre políticos y servidores públicos desarrollada por Hood (2000), siguiendo a Schaffer, como pacto explícito o implícito de los servidores públicos con otros actores del sistema político, acerca de sus derechos y obligaciones y expresado en convenciones informales o en leyes formales. Las dimensiones en que se expresan estos pactos tienen que ver con las competencias (que habilidades se exige por parte de los servidores públicos), las recompensas (qué obtienen los servidores públicos a cambio), y lealtades (qué obtienen los políticos en ese pacto). El modelo tradicional de altos servidores públicos en los países

1 Ver, por ejemplo, Cortázar, Lafuente y Schuster (2014) y Grindle (2012). 
desarrollados (con algunos matices dependiendo su tradición administrativa), ha sido la de competencias de corte generalista (o jurídica en el caso de las tradiciones europeo-continentales), las recompensas asociadas a un alto status y fuerte estabilidad en el empleo, y las lealtades asociadas a la neutralidad política.

Como consecuencia de las reformas inspiradas en el New Public Management, los altos servicios civiles en los países desarrollados, han incorporado estilos gerenciales que han significado importantes cambios sobre la lógica y estructura de estos pactos entre políticos y servidores públicos. Las competencias requeridas son las del manager (no las del analista o generalista), las recompensas son más heterogéneas (pagos por desempeño) y menos asociadas a la estabilidad en el cargo, y las lealtades están más estrechamente vinculadas a la implementación eficiente de las políticas (y menos vinculadas a aquellas del tipo free and frank advice). La intencionalidad subyacente a estos cambios administrativos ha sido la de garantizar un mayor control político sobre el servicio civil y disminuir la excesiva autonomía de la burocracia (Campbell y Wilson, citados en Rouban 2007).

Estos esfuerzos de modernización focalizados en la profesionalización en un segmento directivo diferenciado que opere como reaseguro de una mayor responsiveness de la burocracia se originaron en Estados Unidos, a partir de la creación del Senior Executive Service en 1979. Posteriormente, la adopción de sistemas de alta dirección pública, bajo diferentes formatos, se propagó rápidamente hacia la gran mayoría de los países que integran la OCDE (75\%) (Cortázar, Lafuente, Schuster 2014, Lafuente, Manning y Watkins 2012, Lah y Perry 2008).

El patrón de difusión de las reformas directivas hacia otras latitudes ha seguido un ritmo más lento. En el caso particular de América Latina, han sido escasas las iniciativas de modernización dirigidas a la profesionalización de los altos ejecutivos, donde la confianza política sigue siendo el criterio predominante para la provisión de cargos jerárquicos (Cortázar, Fuenzalida y Lafuente 2016). La transición hacia una lógica gerencial, a nivel de los sistemas de alta dirección pública en nuestra región, tiene efectos muy distintos a la de los países desarrollados, ya que no significa un tránsito desde un sistema de mérito hacia uno de corte gerencial, sino uno que pretende ir desde uno basado en la lógica del patronazgo, hacia uno predominantemente de tipo meritocrático-gerencial. En este marco, a diferencia de lo que sucedió en un grupo de democracias desarrolladas, donde los sistemas de alta dirección pública fueron adoptados con el objeto de garantizar una mayor liderazgo político sobre el aparato estatal, en un 
contexto dominado por las prácticas de patronazgo como el latinoamericano, estas iniciativas apuntan tanto a establecer barreras al avance de la política sobre la administración pública como a instalar capacidades directivas para expandir la profesionalización hacia las distintas esferas administrativas.

Esto significa un desafío mayúsculo para nuestros sistemas de gobierno, con administraciones públicas fuertemente politizadas y acostumbradas a orientarse por la lógica de la confianza política y no del mérito, y menos aún de la eficiencia gerencial. Sustituir la lógica del patronazgo político por la del mérito de tipo gerencial, implica transformaciones profundas en las tres dimensiones del pacto del tipo spoil system: 1) las competencias ya no estarían asociadas a la pertenencia partidaria o confianza personal; 2) las recompensas ya no están asociadas a retribuciones discrecionales o estabilidad ligada al apoyo del jerarca político; 3) y la lealtad no depende del perfil político del designado (Ramos y Scrollini 2013).

En esta sección se examinan algunas de las iniciativas de profesionalización de las cúpulas burocráticas impulsadas en el orden regional, centrando la atención en sus notas distintivas, su evolución y el desarrollo alcanzado. El análisis abarca cuatro casos: el Servicio Profesional de Carrera de México (2003), el Cuerpo de Administradores Gubernamentales (1984) y el régimen de funciones ejecutivas (1991) adoptados en Argentina, el Sistema de Alta Dirección Pública de Chile (2003) y el Cuerpo de Gerentes Públicos de Perú (2008). 


\section{Tabla 1: Los casos seleccionados en perspectiva comparada}

Chile

México

Argentina

$\begin{array}{cc}\text { Dimensión } & 1.311 \text { altos } \\ \text { directivos } & \text { públicos } \\ \text { (superior a la } \\ \text { cantidad de } \\ 750 \text { puestos } \\ \text { originalmente } \\ \text { prevista por la } \\ \text { ley) }\end{array}$

Modalidad de contratación

Contexto de emergencia de las reformas
Contrato de empleo para por período determinado. Permanencia sujeta a desempeño

$$
\begin{aligned}
& \text { Escándalo de } \\
& \text { corrupción } \\
& \text { acelera } \\
& \text { aprobación de } \\
& \text { proyecto en } \\
& \text { gestación }
\end{aligned}
$$
puesto específico,

Perú

Cuerpo de

Administradores

Gubernamentales

Decreto 3.687/84, creación del Cuerpo de Administradores Gubernamentales

Decreto 993/91, creación del régimen de funciones ejecutivas en el marco del

Sistema Nacional de la Profesión Administrativa

(SINAPA)
Abarca todos los cargos de conducción y mandos medios del gobierno federal (36.000 cargos aproximadamente)
160 administradores gubernamentales (incorporación suspendida)

1.298 cargos con funciones ejecutivas (2006)
Cuerpo de Gerentes Públicos

Decreto Legislativo 1.024/2008, creación del Cuerpo de Gerentes Públicos

Ley del Servicio Civi 30.057/13 establece régimen para directivos públicos

377 gerentes públicos superior a la cantidad inicialmente planificada de 350 posiciones)

28.000 directivos alcanzará el régimen previsto en la nueva ley

Contrato de
empleo para puesto
específico, por
período determinado.
Permanencia sujeta a
desempeño

Administradore gubernamentales, con contrato permanente dentro de un cuerpo profesional transversal con doble dependencia. Área de función pública financia, institución de destino asigna tareas

Modelo de empleo para asignación funciones ejecutivas

Gerentes públicos, con contrato dentro de un cuerpo profesional

transversal.

Permanencia sujeta a demanda efectiva de las instituciones y al desempeño

Modelo de empleo para gestión cargos directivos

El Partido Acción Nacional (PAN) llega al poder después de décadas de gobierno del Partido Revolucionario Institucional (PRI)
Administradores gubernamentales, Gurante el primer gobierno democrático

(Alfonsín, Partido

Radical) posdictadura

Funciones ejecutivas. Contexto de crisis económica
Con los gerentes públicos. Se retoma el

impulso para la fesionalización, después de un ciclo de reformas frustradas

Nuevo régimen para posiciones directivas. Experiencia positiva de los gerentes públicos 
Chile México Argentina Perú

\begin{tabular}{|c|c|c|c|c|}
\hline \multirow[t]{2}{*}{$\begin{array}{l}\text { Contexto de } \\
\text { emergencia de las } \\
\text { reformas }\end{array}$} & $\begin{array}{l}\text { Escándalo de } \\
\text { corrupción } \\
\text { acelera } \\
\text { aprobación de } \\
\text { proyecto en } \\
\text { gestación }\end{array}$ & $\begin{array}{l}\text { El Partido Acción } \\
\text { Nacional (PAN) llega } \\
\text { al poder después } \\
\text { de décadas de } \\
\text { gobierno del Partido } \\
\text { Revolucionario } \\
\text { Institucional (PRI) }\end{array}$ & $\begin{array}{l}\text { Administradores } \\
\text { gubernamentales, } \\
\text { durante el primer } \\
\text { gobierno democrático } \\
\text { (Alfonsín, Partido } \\
\text { Radical) posdictadura } \\
\text { Funciones ejecutivas. } \\
\text { Contexto de crisis } \\
\text { económica }\end{array}$ & $\begin{array}{l}\text { Con los } \\
\text { gerentes } \\
\text { públicos. Se } \\
\text { retoma el } \\
\text { impulso para la } \\
\text { fesionalización, } \\
\text { después de } \\
\text { un ciclo de } \\
\text { reformas } \\
\text { frustradas }\end{array}$ \\
\hline & & & & $\begin{array}{c}\text { Nuevo régimen } \\
\text { para posiciones } \\
\text { directivas. } \\
\text { Experiencia } \\
\text { positiva de } \\
\text { los gerentes } \\
\text { publicos }\end{array}$ \\
\hline \multirow[t]{2}{*}{$\begin{array}{l}\text { Objetivos de la } \\
\text { reforma }\end{array}$} & $\begin{array}{c}\text { Despolitización } \\
\text { de segmento } \\
\text { directivo. } \\
\text { Transparencia }\end{array}$ & $\begin{array}{l}\text { Despolitización } \\
\text { y renovación de } \\
\text { cuadros directivos }\end{array}$ & $\begin{array}{c}\text { Desarrollo de } \\
\text { masa crítica para } \\
\text { democratización y } \\
\text { reestructuración del } \\
\text { Estado }\end{array}$ & $\begin{array}{c}\text { Gerentes } \\
\text { públicos } \\
\text { como agentes } \\
\text { de cambio e } \\
\text { innovación. } \\
\text { Esquema } \\
\text { transitorio } \\
\text { para extender } \\
\text { concursabilidad }\end{array}$ \\
\hline & & & & $\begin{array}{l}\quad \text { Nuevo } \\
\text { régimen- } \\
\text { Establecer un } \\
\text { sistema para la } \\
\text { generalidad de } \\
\text { los directivos } \\
\text { públicos }\end{array}$ \\
\hline $\begin{array}{l}\text { Trayectorias de las } \\
\text { reformas }\end{array}$ & $\begin{array}{l}\text { Proceso de } \\
\text { stitucionalización } \\
\text { y expansión }\end{array}$ & $\begin{array}{c}\text { Proceso de } \\
\text { esinstitucionalización }\end{array}$ & $\begin{array}{c}\text { Proceso de } \\
\text { estancamiento } \\
\text { (Administradores } \\
\text { gubernamentales) y } \\
\text { desinstitucionalización } \\
\text { (funciones ejecutivas) }\end{array}$ & $\begin{array}{c}\text { Proceso de } \\
\text { itucionalización } \\
\text { y expansión }\end{array}$ \\
\hline
\end{tabular}

\section{MÉXICO: DEL INICIAL ENTUSIASMO REFORMISTA AL PROGRESIVO} RETORNO A LA DESCONFIANZA POLÍTICA EN LA BUROCRACIA

En el año 2003, por primera vez, México impulsa un proceso de modernización administrativa orientado a instaurar una burocracia meritocrática en sustitución de un arraigado sistema de botín político que había imperado por más de setenta años en el país. En un contexto de alternancia político-partidista, se aprueba la Ley del Servicio Profesional de Carrera (LSPC) (2003) con la finalidad de profesionalizar el segmento de cargos directivos de nivel medio y alto, hasta ese momento designado en base a criterios de confianza (Martínez Puón 2009, Grindle 2012). Los esfuerzos de reforma se focalizaron en una pequeña franja de cargos jerárquicos para evitar un eventual bloqueo de los poderosos sindicatos de 
agentes estatales, pero con la intención de extender el sistema al resto del aparato público. Se buscaba establecer barreras a la enraizada politización a través de la creación de un sistema de empleo público sustentado en el mérito, la igualdad de oportunidades y la eficiencia (Strazza 2014, Dussauge Laguna 2011, Iacoviello, Rodríguez Gustá y Cruz Orozco 2006). Pese al generalizado apoyo legislativo a la Ley de Servicio Profesional de Carrera (LSPC), desde sus orígenes el nuevo sistema de mérito fue resistido (Pardo 2015) por el rol central que históricamente desempeñó el patronazgo. Es que bajo aquel sistema, se daba de manera generalizada el manejo discrecional de las posiciones gerenciales para la construcción y sostenimiento del poder político. El aparato estatal era concebido como un apéndice manipulable y flexible de la estabilidad del sistema político (Arrellano Gault 2008).

Se instrumentó una reforma de amplio alcance a un ritmo acelerado. El nuevo sistema debía operar sobre un segmento de aproximadamente 36.000 puestos de confianza, posicionado entre los altos cargos políticos y los agentes de base o sindicalizados, en un término máximo de tan solo tres años. En los plazos previstos por la norma se implantó el servicio profesional en 77 dependencias y órganos desconcentrados del administración pública federal central (Strazza 2014, Rivas et al. 2013).

El diseño original de la función directiva pública, contemplado en la LSPC, se aproximaba a un modelo de gestión de recursos humanos de empleo (Martínez Puón 2009). El sistema se estructuraba, bajo una lógica integrada, en distintos componentes: 1) planeación de recursos humanos; 2) ingreso; 3) desarrollo profesional; 4) capacitación y certificación de capacidades; 5) evaluación del desempeño; 6) separación; y 7) control y evaluación (Iacoviello, Rodríguez Gustá y Orozco 2006). Los esfuerzos se focalizaron preponderantemente en los procesos de reclutamiento y selección (Rivas et al. 2013).

La normativa establecía un sistema mixto que combinaba mecanismos de acceso cerrados y abiertos. Preveía procesos de concursos diferenciados para postulantes internos y externos, incluida la reserva de aspirantes , con instancias específicas de certificación para el caso de los servidores públicos. Los concursos y las vacantes a cubrir debían ser publicados en el Diario Oficial de la Federación, además de estar disponibles en la página electrónica de la Secretaría de la Función Pública. Dicho portal se constituía en la única vía para concursar a un puesto sujeto a la Ley de Servicio Profesional de Carrera (Iacoviello, Llano, Strazza 2012, Martínez Puón 2009). 
El nuevo instrumental legal buscaba proteger a los funcionarios políticos frente a eventuales desvinculaciones arbitrarias, no obstante, no les reconocía el derecho a la estabilidad, puesto que eran susceptibles de ser removidos por razones técnicas ligadas, principalmente, al desempeño (Iacoviello, Rodríguez Gustá y Orozco 2006). El rendimiento de los funcionarios era evaluado en base al logro de metas individuales e institucionales. Además de estar atados a la permanencia en el cargo, los resultados de las evaluaciones debían servir como parámetros para promociones y otorgamiento de estímulos salariales (Strazza 2014, Martínez Puón 2009).

La LSPC distribuía la responsabilidad de gestionar el servicio profesional entre varios actores y niveles de decisión y ejecución, desde la Secretaría de la Función Pública (SFP) y su Consejo Consultivo, a cargo de establecer la normativa general y el diseño de la gestión de recursos humanos, seguidos por los Comités de Selección y Técnicos de Profesionalización y las Direcciones de Recursos Humanos de cada dependencia, a los que les era asignado un papel operativo central. La gobernanza del servicio civil se complementó con la creación, en el ámbito de la Secretaría, de una entidad experta, la Unidad de Recursos Humanos y Profesionalización de la Administración Federal. Su misión era coordinar el trabajo de los comités y direcciones de recursos humanos de los distintos organismos. Pero más allá del esquema de implementación descentralizado del servicio de carrera inicialmente previsto, la primera reglamentación de LSPC concentró las potestades de ejecución y control en la Secretaría de la Función Pública (Iacoviello, Rodríguez Gustá y Cruz Orozco 2006, Martínez Puón 2009, Pardo 2005).

Esta primera fase de la reforma, que se extendió desde la aprobación del primer reglamento de la LSPC (2004) hasta el final del mandato del presidente Fox (2000-2006), se caracterizó por una alta priorización política y una dinámica intensa de implementación. Pero las fuertes críticas hacia la disfuncionalidades del sistema y los intentos de modificación de la LSPC que proliferaron a pocos años de su aprobación, dieron inicio a una segunda etapa del proceso de modernización (2006-2012), signada por la continuidad de la reforma en un contexto de baja priorización y una creciente flexibilización, seguida del cuasi desmantelamiento del sistema (2013-2014). En un marco de escepticismo y renuencia política hacia el servicio civil, durante las dos últimas fases los recambios gubernamentales, incluso entre referentes de un mismo partido político, fueron acompañados de una mecánica remoción y reinstalación de obstáculos que favoreció la desinstitucionalización del servicio civil. Los gobiernos entrantes flexibilizaban las reglas para nominar discrecionalmente a seguidores y 
despedir arbitrariamente a detractores, y los salientes reintroducían trabas con el fin de proteger a sus allegados (Strazza 2014, Grindle 2012).

Durante la antesala y los primeros años del gobierno de Calderón (20062012) el sistema fue objeto de diversos embates políticos, algunos infructuosos, que contribuyeron a debilitarlo. En el período preelectoral se impulsaron iniciativas legales para excluir a una serie de puestos de la aplicación de la ley o para reducir requisitos de ingreso al sistema, todo ello con vistas a ampliar las oportunidades de patronazgo ante un eventual triunfo en las urnas. Posteriormente, el nuevo gobierno, no obstante pertenecer a las mismas filas políticas que su predecesor, despidió injustificadamente a más de 1.000 servidores de carrera entre el 2007 y 2008 (Dussauge Laguna 2011, Martínez Puón 2008). Finalmente, a raíz de diversos cuestionamientos a las deficiencias del funcionamiento del sistema se aprobó un nuevo reglamento que, bajo la apariencia de una solución técnica a los problemas detectados, buscó ampliar los márgenes para designar discrecionalmente (Dussauge Laguna 2011).

Desde diversos sectores se objetaba la excesiva centralización de los procedimientos en manos del órgano rector, el uso de indiscriminado de nominaciones transitorias, la benevolencia de las evaluaciones del desempeño, entre otros aspectos. Frente a ese clima de opinión adverso, el gobierno se valió de los aportes técnicos provistos por instituciones especializadas para diseñar un nuevo reglamento que le permitiera reducir el alcance del sistema para extender el control político sobre la burocracia (Martínez Puón 2009, Pardo 2015). El dispositivo desconcentraba potestades operativas hacia las agencias y las hacía corresponsables de la gestión, a la vez que preservaba en la SFP la capacidad de supervisión, control y centralización de la información. Pero ante la ausencia de mecanismos de accountability efectivos para garantizar la fiscalización de la SFP sobre las agencias, en la práctica, la mayor delegación dio lugar a la repolitización del sistema, principalmente, mediante el incremento exponencial de las contrataciones excepcionales. El uso combinado de nominaciones provisorias (Artículo 34) con el ejercicio del poder de veto intensificó el desembarco de personas política y personalmente afines en los organismos. El sistema era manipulado mediante la designación transitoria de personas cercanas al poder, quienes en virtud de la experiencia adquirida durante el ejercicio temporal del cargos y el bloqueo ejercido por las autoridades a los postulantes no preferidos, tenían más que allanado el camino para ganar arbitrariamente el concurso. Estas prácticas, junto a los despidos arbitrarios, suscitaron el progresivo descreimiento generalizado en el sistema de mérito, redundando en una disminución de los postulantes a los concursos. El clientelismo y el patrimonialismo volvieron a ser 
percibidos por la opinión pública como instituciones informales prevalecientes en la administración pública (Strazza 2014, Dussauge Laguna 2011, OCDE 2011, Arrellano Gault 2013).

La asunción de un gobierno de signo político distinto (PRI) marca el inicio de la tercer fase de reforma (2013-2014) en la que buena parte de las decisiones en materia de gestión de recursos humanos se deriva de la fuerte desconfianza hacia la burocracia heredada y de amplias expectativas partidistas de retomar el control político sobre las posiciones jerárquicas. El nuevo gobierno, encabezado por el presidente Peña Nieto, descreía de la neutralidad de los ocupantes de los cargos ejecutivos a raíz del uso abusivo de las nominaciones transitorias y de la adulteración de los concursos por parte del gobierno anterior. A su vez, las fuertes críticas hacia la sustanciación de cuantiosos concursos amañados para proteger a sus seguidores en vísperas al recambio gubernamental, agudizaron las sospechas sobre la imparcialidad de los agentes (El Economista 2013). Todo ello dio lugar a que el partido (PRI) del nuevo gobierno en ascenso retomara viejas iniciativas legislativas orientadas a bajar la línea divisoria entre los segmentos políticos y la burocracia profesional, suprimiendo a los puestos directivos más elevados (casi 4.000 plazas) de las regulaciones de la LSPC. Esta modificación habilitó al Presidente no solo a despedir a los funcionarios identificados con el gobierno precedente sino también a colocar en lugares estratégicos del estado a personas de su preferencia (Pardo 2015, Aristegui Noticias 2012).

Otra señal de desconfianza en el sistema edificado por los gobiernos anteriores fue el intento de la nueva gestión de sustituir a la SFP por un organismo a cargo de la lucha contra la corrupción. Si bien esta medida no logró suprimir al órgano rector, el desacuerdo con el sistema se materializó con la reducción del personal de la unidad especializada a cargo de la gestión del sistema que operaba bajo su órbita (Unidad de Políticas de Recursos Humanos) y su virtual funcionamiento a través de la nominación transitoria de un funcionario como titular de la SFP (Strazza 2014). Estas decisiones contribuyeron a profundizar el proceso de debilitamiento del órgano responsable del sistema de carrera, que comenzó a gestarse a partir de la descentralización de potestades en materia de gestión de personal hacia las agencias.

Esta trayectoria de desinstitucionalización del mérito en paralelo a la progresiva pérdida de influencia del órgano responsable de la gobernanza del servicio civil, se revela en los datos proporcionados por un diagnóstico elaborado por el Banco Interamericano de Desarrollo (BID) en el año 2014. La contracción del Índice de Mérito de 47 a 40 puntos durante el período 2004-2013 pone de manifiesto la restitución de los criterios de 
lealtad política y personal para el acceso y desvinculación de los agentes. Asimismo, la disminución de 600 a 80 postulantes para cada concurso entre 2004 y 2013 da signos del creciente descreimiento que ha sufrido el sistema de carrera. Por otra parte, la creciente fragilidad del órgano rector del servicio civil se refleja en el deterioro que ha registrado el subsistema de organización de la función de recursos humanos, descendiendo de 50 a 30 puntos desde el 2004 al 2013 (Strazza 2014, Iacoviello y Strazza 2014).

Argentina: Un ITINERARIO DE MODERniZACIÓN ZIGZAgUEANTE Y DISCONTINUO

La persistente inestabilidad de las reformas administrativas ha convertido a la burocracia estatal argentina en la expresión institucional de un auténtico cementerio de proyectos (Oszlak 1983, Acuña 2008). Y, en particular, el mismo itinerario de sucesivos intentos posteriormente abandonados caracterizó a la trayectoria de las iniciativas de modernización de las franjas directivas públicas.

Se impulsaron dos estrategias sucesivas y superpuestas de profesionalización de los segmentos ejecutivos. Inicialmente se buscó conformar un cuerpo de élite bajo un formato de carrera horizontal mediante una lógica gradual y focalizada. Posteriormente se instituyó un sistema específico para las funciones ejecutivas, próximo al modelo de empleo, en el marco de una reforma más integral y masiva (Negri 2005).

La primera reforma tuvo lugar con posterioridad a la restauración de la democracia. Tomando como base la experiencia de la École Nationale d'Administration (ENA), mediante el Decreto 3.687/84 se creó el Cuerpo de Administradores Gubernamentales (CAG) con el fin de reestructurar el aparato administrativo. Se introducía una nueva franja de cargos bisagra entre el funcionariado político y de línea cuya tarea central sería la de reconstruir la burocracia para ponerla al servicio de la democracia. La idea central era formar una masa crítica y plural de jóvenes administradores altamente formados y motivados que contribuyeran a la consolidación de una nueva cultura y un nuevo estilo de gerencia pública. El diseño preveía un esquema de asignaciones móviles de sus miembros a distintos organismos centralizados y descentralizados para el desempeño de funciones de planeamiento, asesoramiento conducción o coordinación de nivel superior (Piemonte 2005, Pulido 2005, Negri 2005, Oszlak 1994).

Los aspirantes a acceder al CAG debían atravesar por un riguroso proceso de selección polietápico abierto que incluía fases de examinación eliminatorias y de formación especializada. Una vez superadas todas las 
instancias, los miembros ingresaban de forma directa al escalafón específico de administradores gubernamentales. Los funcionarios pueden progresar a lo largo de una carrera estructurada en distintos niveles y grados, en base a las evaluaciones del desempeño y a la acreditación de formación continua (Pulido 2005, Minsky 1997, Oszlak 1994).

Los miembros gozan de permanencia en su condición de integrantes del cuerpo, pero se les aplica un mecanismo rotativo que se activa a pedido de las organizaciones. Los administradores gubernamentales son destinados a diversas instituciones demandantes por un término máximo de tres años, prorrogable por dos años en caso de conformidad entre ambas partes. El carácter móvil de esta red de administradores favorecería una mirada más generalista de las problemáticas de la administración así como también aportaría mayores niveles de coordinación transversal a la acción estatal (Piemonte 2005, Negri 2005).

El cuerpo recibió un fuerte impulso inicial que pronto fue diluyéndose merced a los avatares de la política. El papel de articuladores entre los segmentos políticos y administrativos, atribuido a los administradores gubernamentales, no estaba instalado en la tradición administrativa del país. Este colectivo de élite generaba fuerte resistencia entre funcionarios políticos y agentes de carrera. Los primeros desconfiaban de la autonomía de sus miembros y preferían contar con directivos alineados políticamente a su partido político, mientras que los segundos los percibían como una obstrucción para satisfacer sus expectativas de ascenso (Piemonte 2005, Negri 2005).

El apoyo a la reforma se fue agotando con el devenir de los gobiernos. Nunca se promovió una ley específica (su creación fue provista por un decreto presidencial) que evidenciara un apoyo de un espectro político más amplio que garantizara mayores niveles de compromiso con el sostenimiento de la reforma. Este escaso respaldo redundó en la paralización de las convocatorias a concurso a pocos años de producirse el primer recambio gubernamental del período democrático. El tamaño planificado originalmente era de aproximadamente 1.200 administradores gubernamentales, meta que implicaba una incorporación incremental de administradores en el transcurso de veinticinco años (Oszlak 1994). Pero luego de cuatro convocatorias concretadas hasta la primera gestión menemista (1989-1995), los ingresos al CAG se congelaron . Alo largo de las distintas aperturas fueron promovidos $202 \mathrm{administradores}$ gubernamentales, volumen que se fue achicando a raíz de un programa de retiro voluntario promovido por el gobierno aliancista (1999-2001) (Piamonte 2005). 
El escalafón logró subsistir pese a los intentos de absorción por parte de otras reparticiones, pero sus roles fueron variando de acuerdo a la impronta que dieron los distintos gobiernos. Del rol emblemático en la democratización de la burocracia estatal atribuido en su estadio fundacional, el cuerpo remanente pasó a utilizarse como recurso catalizador de políticas de variada importancia. Con el objetivo de crear una institucionalidad propia frente a los embates del poder político, se fundó Asociación de Administradores Gubernamentales (AAG) con el fin de defender de los intereses de sus miembros y de conformar una organización profesional (Negri 2005).

La experiencia del CAG y, en particular la experticia de sus miembros, colaboraron en el diseño de un régimen especial para los puestos críticos (Negri 2000), institución que en buena medida contribuyó al desplazamiento de ese grupo de élite. Mediante el Decreto 993/91 se creó un sistema específico para cargos con funciones ejecutivas como parte de un sistema extendido de servicio civil, denominado SINAPA, con la finalidad de profesionalizar los cuadros directivos. La iniciativa representaba un avance institucional significativo en el sentido de que el mismo Poder Ejecutivo decidía autoimponerse restricciones al manejo discrecional de las posiciones jerárquicas. Este régimen abarcaba un número limitado de posiciones ejecutivas seleccionadas por su importancia estratégica (Iacoviello, Zuvanic y Tomassi 2003, Salas 2005, Oszlak 1994, Salas y Wegman 2016).

La gestión de los cargos con funciones ejecutivas se organiza bajo un formato de empleo. Se accede a los puestos críticos mediante un proceso de reclutamiento competitivo y abierto que culmina en la elevación de una terna, a propuesta de un comité de selección, para que la máxima autoridad política de la jurisdicción escoja el candidato. El horizonte de permanencia en los puestos críticos es de cinco años, prorrogable por dos años más en caso de alto rendimiento. Durante ese período se les reconoce estabilidad funcional y solo pueden ser desvinculados por razones disciplinarias, desempeńo deficiente o por supresión del puesto, siempre que no se genere un cargo equivalente. Los funcionarios son evaluados en base a una combinación de factores y resultados preestablecidos por la autoridad superior (Salas 2005, Iacoviello y Tomassi 2002).

Con el tiempo el Sistema de Funciones Ejecutivas fue perdiendo vitalidad y cediendo espacio a la discrecionalidad. La laxitud del diseño primigenio y las prácticas sesgadas propiciaron la politización del sistema. En primer lugar, la ausencia de un procedimiento reglado para definir cuáles eran los cargos con funciones ejecutivas, favoreció una distribución 
de los puestos críticos entre las distintas jurisdicciones asociada más a criterios políticos que técnicos. En segundo lugar, el sistema no ofrecía suficientes garantías para evitar la arbitrariedad: la autoridad convocante proponía los integrantes del órgano selección, los métodos de evaluación eran establecidos de manera ad-hoc por el comité y las ternas no se configuraban de acuerdo a un orden de mérito. Finalmente, el extendido uso de nominaciones transitorias contribuía a saltear sistemáticamente los procedimientos de selección (Salas 2005, Iacoviello y Tomassi 2002, Salas y Wegman 2016). Esta práctica, a su vez, restringía la cobertura del sistema de evaluación del desempeńo, dado que solo opera sobre los directivos que ingresan bajo la modalidad prevista por la ley.

Se intentó subsanar formalmente las inconsistencias técnicas del sistema en el marco del Convenio Sectorial del Sistema Nacional de Empleo Público (SINEP, ex SINAPA). A los fines de acotar el margen de discrecionalidad, se precisó el mecanismo de selección aplicable a los cargos críticos y se previó la definición de un orden de mérito para los ternados (Salas y Wegman 2016). Pero este perfeccionamiento legal no logró reimpulsar el régimen, y en su lugar, se profundizó su desinstitucionalización. La totalidad de las funciones ejecutivas en el SINEP se ocuparon por la vía de designaciones transitorias. Recién en 2014, en vísperas a la conclusión del tercer mandato kirchnerista, los cargos directivos críticos fueron incluidos en los procesos de cobertura -que se habían iniciado en el año 2009-, para su provisión mediante concursos (Zuvanic 2016, Iacoviello y Llano 2017).

La vulneración constante de las reglas ha impedido la institucionalización del sistema de alta dirección en Argentina. El predominio de la confianza política sobre el componente técnico ha limitado la conformación de un cuerpo directivo profesionalizado que contribuya al desarrollo y sostenibilidad de las políticas públicas. La transitoriedad, la discrecionalidad y la volatilidad de las nominaciones, reflejada en una baja antigüedad promedio (tres años) en el ejercicio de funciones ejecutivas, constituyen claros indicios del deterioro del sistema (Coutinho 2016, Iacoviello y Llano 2016).

\section{Chile: Legitimidad INCREMENTAL CON LAPSOS DE DESALINEAMIENTOS}

A lo largo de las últimas dos décadas Chile se embarcó en un proceso de modernización administrativa bajo una lógica incremental, pero progresivamente comprehensiva, y con unafuerteimpronta neogerencialista. Una crisis político-institucional, desatada en el 2002 a raíz de una serie de 
escándalos de corrupción, propició el impulso de un paquete de acuerdos suscriptos entre el gobierno y la oposición que contribuyó a intensificar el ritmo de las reformas (Alberts, Dávila y Valenzuela, citados en Llano 2014, Alessio y Pacheco 2015, Silva 2011).

Uno de los productos del conjunto de medidas fue la aprobación de la Ley de Nuevo Trato Laboral (LNTL) (19.882) en el año 2003. Subyacía a esta norma la adopción de una estrategia de reforma consistente en cortar el servicio civil en dos pisos independientes entre sí: el segmento de cargos directivos y el segmento de puestos de carrera. Los esfuerzos se enfocaron en la profesionalización de la franja gerencial, mediante la creación de un Sistema de Alta Dirección Pública (SADP), por su viabilidad política y fiscal y por su potencial influencia para mejorar el desempeño de las agencias. Se suponía que el SADP se constituiría en una suerte de nave insignia del proceso de modernización, favoreciendo la propagación de la profesionalización hacia los escalones inferiores de la burocracia (Cortázar Velarde 2011, Iacoviello 2010).

El SADP representaba una ruptura con el arraigado sistema de cuoteo para la provisión de cargos ejecutivos, pero preservaba para la clase política ciertas prerrogativas del viejo modelo a los efectos de garantizar la gobernabilidad democrática $\mathrm{y}$, de ese modo, la aceptabilidad política del proyecto. El diseño apuntaba a establecer un punto de equilibrio entre mérito y responsiveness. En tal sentido, el nuevo sistema introducía mecanismos de selección competitivos para la cobertura de cargos directivos de primer y segundo nivel jerárquico, reclutados hasta ese momento de manera discrecional y, a la vez, mantenía criterios de confianza política para definición final del candidato por parte de las máximas autoridades políticas así como para su desvinculación (Grindle 2012, Longo 2013, Waissbluth 2008).

La LNTL también previó la conformación de dos organismos con responsabilidades en el desarrollo del SADP. Dio origen a una nueva institucionalidad a cargo de la rectoría del servicio civil, denominada Dirección Nacional del Servicio Civil, con injerencia directa en el funcionamiento e implementación del SADP. También creó el Consejo de Alta Dirección Pública, organismo autónomo y plural, compuesto por consejeros que representan a las dos fuerzas mayoritarias del país, cuya función es la de velar por el cumplimiento de los procesos de selección del SADP. Los miembros son designados por el Presidente de la República y ratificados por el Senado, duran seis años en sus funciones y se renuevan alternadamente por duplas cada tres años (Silva 2011, Ramírez Alujas, citado en Iacoviello 2009). 
El nuevo sistema fija filtros de mérito para el acceso a posiciones gerenciales bajo un modelo de empleo. Los directivos son incorporados mediante concursos públicos y abiertos para el ejercicio de un puesto específico (Egaña 2014, Cortázar Velarde 2011). El proceso de concurso se inicia con la convocatoria a través de los medios de comunicación masivos, la prensa escrita, la página web del Servicio Civil, el Diario Oficial y de un sistema de postulación en línea denominado SPEL. Posteriormente, una empresa especializada evalúa los antecedentes y entrevista de los aspirantes para luego elevar una nómina de preseleccionados al órgano colegiado que interviene en la selección. Dependiendo del cargo y del nivel jerárquico, el CADP (en el caso de cargos de nivel I) o un Comité de Selección designado por este (en el caso de cargos de nivel II), elige a los mejores candidatos y luego de entrevistarlos personalmente, elabora una nómina corta, con no menos de tres y no más de cinco candidatos, que es propuesta a la autoridad facultada para el nombramiento final, ya sea el Presidente, Ministro o Jefe del Servicio correspondiente (Iacoviello, Llano y Strazza 2012, DNSC 2016).

En los tres primeros meses de su designación, los ADPs y su superior jerárquico suscriben convenios de desempeño que incluyen metas y objetivos de resultados a alcanzar. Los directivos son designados por un plazo de tres ańos, prorrogable por dos períodos, con la posibilidad de ser removidos por razones de índole política o por rendimiento deficiente durante todo ese lapso (Llano 2014, Cortázar Velarde 2011).

La reforma ha seguido una trayectoria acumulativa, cuyo ritmo se ha acelerado frente a presuntos casos de corrupción y en el contexto de recambios de gestión. La alternancia de coaliciones de gobierno ha ido acompañada de prácticas que amenazaron la vitalidad del sistema, como el uso expandido de desvinculaciones y las recurrentes designaciones provisorias, entre otras maniobras elusivas. Pero en lugar de agudizar la contracción del sistema, los sucesivos gobiernos han respondido a los cuestionamientos que suscitaron tales manejos mediante el perfeccionamiento y expansión del sistema (Llano 2014).

La LNTL preveía la incorporación inmediata de 415 cargos directivos con la proyección de alcanzar escalonadamente un total de 750 puestos, distribuidos en 100 servicios, en el año 2010. Esa meta se superó con creces y la cobertura del sistema se ha extendido hacia servicios, niveles y poderes de gobiernos no adscritos originalmente al sistema. Como reflejo de este crecimiento, los cargos afectados al SADP aumentaron un 300\% desde su puesta en marcha, alcanzando actualmente a 1.311 puestos directivos (233 de I Nivel jerárquico y 1.078 de II Nivel jerárquico). Todo 
este proceso ha ido acompañado de un progresiva institucionalización y legitimación de la Dirección Nacional de Servicio Civil como actor central del servicio civil chileno (Llano 2014, Cortázar Velarde, Lafuente y Schuster 2014, Egańa 2016).

El SADP ha logrado ser percibido como un mecanismo fiable de acceso al Estado, convirtiéndose paulatinamente para la dirigencia política en un recurso de legitimación de los procesos de selección. Adicionalmente, el efecto profesionalizador ha ido decantando hacia los restantes niveles de la burocracia chilena, permeando al estado con los principios de mérito y transparencia. El crecimiento del Índice de Mérito, medido por el BID, de 60 a 67 puntos entre 2004 y 2013 evidencia la tendencia hacia la ascendente profesionalización del servicio civil (Longo 2013, Llano 2014, Egaña 2016, Iacoviello y Strazza 2014).

Más allá de estos avances y de los sucesivos ajustes introducidos, prevalece la percepción de que el SADP debe enfrentar al menos tres desafíos para afianzar su institucionalización: 1) los altos niveles de rotación; 2) el amplio uso de las designaciones provisorias; y 3) el desarrollo hipertrofiado del sistema de selección en detrimento de los restantes componentes del SADP. La duración de los ADPs en sus puestos no excede los dos ańos y medio. La alta tasa de desvinculación, principalmente en las etapas de alternancia política, y la infrecuente prórroga de las designaciones han favorecido la baja permanencia de los directivos. La volatilidad de los directivos redunda en una pérdida de capacidades directivas adquiridas e impacta negativamente en la estabilidad de las políticas públicas, además de generar altos costos fiscales. Por otra parte, la excesiva transitoriedad de las nominaciones desalienta las postulaciones al prevalecer la idea de que el sistema se aplica para convalidar a quien ejerce el cargo, resintiendo la confianza pública en el sistema. Se ha señalado también que el fuerte énfasis en el fortalecimiento de los mecanismos de acceso ha operado en menoscabo del desarrollo de las restantes dimensiones del SADP, corriendo el riesgo de reducir el papel del SADP al de una mera agencia de selección de directivos públicos (Egaña 2016, Inostroza, Morales Cassetti y Fuenzalida 2011, Egaña 2014, Peftouloglou 2015, Longo 2013).

A fin de subsanar parte de estas persistentes tensiones que presenta el sistema, en el 2015 la actual gestión impulsó un proyecto de ley orientado a seguir expandiendo el sistema, reducir el impacto de las sucesiones gubernamentales e introducir incentivos para retener el capital directivo desarrollado, entre otras medidas. Se busca mermar la incidencia de la rotación política mediante la objetivación de las desvinculaciones y la eliminación de las figuras de directivos transitorios y provisionales y su 
sustitución por un esquema de subrogancias. Para descomprimir la resistencia política que ocasionalmente susciten disposiciones de tal naturaleza, en compensación se reserva una cantidad máxima de cargos directivos de primer nivel (12) para ser nominados de forma directa durante los primeros meses de gobierno. Adicionalmente, con el espíritu de resguardar las capacidades ejecutivas adquiridas y optimizar la eficacia de los procesos de selección, se propone la inclusión de ex directivos en los concursos, por razones fundadas, y la creación de un banco de candidatos con los participantes en instancias de competencias previas. La iniciativa fue aprobada por el Congreso Nacional en agosto del 2016 con el apoyo de todo el arco político (CDC 2015, DNSC 2016).

Esta modificación apunta a generar un espacio directivo con mayores niveles de estabilidad que trascienda los cambios gubernamentales en el marco de una revisión del enfoque predominante de reforma. Sin abandonar el basamento neogerencialista que inspiró el diseño inicial del SADP, se introducen innovaciones asociadas al neoweberianismo, corriente que entre otros aspectos realza la centralidad de la integridad de los directivos para la consecución del interés colectivo (Llano 2015). Concretamente, ese giro doctrinario se materializa en la formalización de lineamientos para la elaboración de códigos de ética.

\section{Perú: Trayectoria Ascendente con focos De Resistencia}

En el año 2008 se logra revertir en el estado peruano un extenso ciclo de fallidos intentos de reformas administrativas integrales mediante la adopción de una estrategia focalizada y gradual que fue progresivamente sedimentando las bases de un proceso de sostenida profesionalización del servicio civil que ha logrado trascender los gobiernos. En uso de facultades delegadas, mediante la emisión de una serie de decretos, el presidente Alan García (2006-2011) definió una agenda de reformas mínimas orientada a fortalecer la institucionalidad del servicio civil e instalar capacidades directivas en las cúpulas administrativas para propagar la modernización hacia todo el aparato estatal en un plazo estimado de diez ańos. Efectivamente, los avances concretados a partir de este paquete de disposiciones, sirvieron de plataforma para la instrumentación de cambios más globales, materializados en una nueva Ley de Servicio Civil en 2013 (Cortázar Velarde 2014, Iacoviello 2015).

El contexto de gestación de la reforma estaba signado por una elevada politización del aparato administrativo. El servicio civil peruano era considerado como uno de los más frágiles de la región, según una evaluación realizada por el BID en (2004). El sistema de empleo público se encontraba 
en un estadio de desarrollo preburocrático en el que predominaban la discrecionalidad y el arbitrio. Los cargos jerárquicos, en particular, eran mayoritariamente provistos por criterios de confianza política (Corrales Angulo 2014a, Corrales Angulo, citado en Iacoviello 2015). Los cambios apuntaban a suplantar paulatinamente ese sistema de patronazgo hondamente arraigado por un sistema basado en el mérito.

La consolidación de una agencia de carácter ejecutivo y la renovación de los directivos eran considerados factores clave para liderar ese proceso de reforma. A tales fines se creó la Autoridad Nacional del Servicio Civil (SERVIR) (Decreto Legislativo 1023), como órgano rector del sistema de gestión de recursos humanos, con la responsabilidad inicial de diseñar un nuevo servicio civilygestionar los cuadros ejecutivos. Complementariamente se instituyó el Cuerpo de Gerentes Públicos (CGP) con el fin de desarrollar competencias directivas mediante la incorporación meritocrática de sus integrantes y contribuir a extender la profesionalización hacia los restantes estamentos administrativos. El CGP fue concebido como un esquema transitorio que serviría de laboratorio para la posterior expansión del modelo al conjunto de directivos públicos. La idea presentaba la ventaja de inyectar un shock de capacidad gerencial a la administración a un costo fiscal abordable (Cortázar Velarde, Lafuente y Schuster 2014, Iacoviello 2015, Iacoviello 2011, Corrales Angulo 2010, Corrales Angulo 2014a, Cortázar Velarde 2014).

El cuerpo está constituido por un pool de gerentes que son asignados a agencias solicitantes. Se introdujo el componente voluntario al diseño a fin de evitar la resistencia que generaría la imposición de un nuevo directivo y, de ese modo, asegurar la viabilidad política de la iniciativa. El nuevo colectivo se integraría paulatinamente hasta alcanzar, al menos, los 350 miembros para el ańo 2013 (Cortázar Velarde 2014, Iacoviello 2015). Los Gerentes Públicos gozan de estabilidad, pero su permanencia está sujeta al desempeńo satisfactorio, al carácter transitorio del servicio y a la efectiva demanda de las entidades de destino. Si los directivos no logran ser recolocados, pasan a una situación de disponibilidad que se ha extendido de uno a tres años para preservar el talento alcanzado y evitar los embates de los ciclos electorales. La temporalidad de las asignaciones -tres años, prorrogables por dos años más- le imprime una fuerte dosis de flexibilidad y dinamismo al sistema (Corrales Angulo, citado en Iacoviello, Llano y Strazza 2012, Decreto Legislativo 1.024, Corrales Angulo 2014a).

Los gerentes pueden ser incorporados por medio de tres modalidades de selección: 1) ordinaria; 2) simplificada, en la que solo participan ex gerentes públicos que fueron excluidos por vencimiento de plazo de disponibilidad 
y postulantes que llegaron a instancias finales en procesos abiertos anteriores; y 3) articulada con la Escuela Nacional de Administración Pública (ENAP), en la que se inserta una instancia de formación a cargo de dicha institución.

El proceso de selección es conducido centralizadamente por SERVIR e incluye dos etapas con subfases eliminatorias, una de reclutamiento y selección, y otra denominada curso de introducción. La primera etapa comienza con la postulación a través de un portal institucional de SERVIR y abarca sucesivas instancias de evaluación curricular, prueba de conocimientos y psicotécnicas y entrevista por competencias, que culminan en la conformación de una terna con los candidatos mejor puntuados. En la segunda etapa los postulantes deben superar una evaluación de casos prácticos y pasar por un assessment center para recién acceder a una entrevista con los miembros del Consejo Directivo de SERVIR. La gran mayoría de estas fases inicialmente se externalizaban en empresas privadas con el propósito de reducir el riesgo de intromisión política en las nominaciones, pero SERVIR fue absorbiendo algunas de esos estadios con el objeto de reducir los costos de las tercerizaciones. Este desplazamiento de actores ha sido señalado como una potencial amenaza a la imparcialidad del proceso (Corrales Angulo 2014a, Cortázar Velarde, Lafuente y Fuenzalida 2016, Iacoviello 2015).

El órgano rector ha buscado garantizar un alto nivel de transparencia de los procesos de selección mediante una amplia difusión de las convocatorias, la publicación de los resultados parciales y finales de las competencias y la veeduría de la Asociación Civil Transparencia (ACT). Estas medidas parecen haber sido eficaces a la luz de las encuestas de seguimiento realizadas por la ACT, en las que se evidencia un reconocimiento casi generalizado (98\%) de la transparencia y el carácter meritocrático de los procedimientos de reclutamiento de los gerentes públicos (Corrales Angulo 2014a, SERVIR citado en Iacoviello 2015).

Una vez que se integran al cuerpo, los gerentes públicos suscriben un convenio de asignación con SERVIR en el que se fijan metas de desempeño. Adicionalmente, los nuevos gerentes firmas un convenio marco con la entidad de destino en el que se fijan compromisos de mayor envergadura (Iacoviello 2015).

La trayectoria de institucionalización del CGP ha sido ascendente, con algunos focos de resistencia en el ámbito subnacional. El sistema ha evidenciado cierta sensibilidad a los cambios de gobierno regionales, expresada en la conclusión de las asignaciones de gerentes públicos en los 
destinos locales. Pero el CGP se ha mostrado mucho más sólido en el plano nacional, donde la alternancia gubernamental no disparó el porcentaje de las desvinculaciones por encima de los parámetros habituales. El sistema se ha consolidado, superando el tamaño del cuerpo originalmente planificado (350 gerentes públicos) y ampliando el espectro de entidades demandantes, hasta incluso extenderse a otros poderes del Estado. Este proceso de fortalecimiento del CGP, fue acompañado de un creciente afianzamiento y legitimación de SERVIR como órgano rector del servicio civil (Corrales Angulo y Martín 2012, Iacoviello 2011, Cortázar Velarde 2014, Iacoviello 2015). El incremento del Índice de Desarrollo del Servicio Civil de 14 a 29 puntos en el período 2004-2014 pone de manifiesto este progresivo afianzamiento del sistema (Iacoviello y Strazza 2014).

El CGP operó como instancia experimental que sirvió de base para encarar una reforma integral del servicio civil, materializada en la aprobación de la Ley de Servicio Civil 30.057 en el 2013. La nueva norma busca expandir el modelo del CGP a los 28.000 directivos que se desempeñan en los tres niveles de gobierno, y establecer un régimen único de carrera bajo un esquema de gradualidad. Se mantiene como modalidad de ingreso a los cargos directivos los concursos abiertos, pero en este caso se descentralizan los procesos de selección en las entidades públicas, con la posibilidad delegar parcial o totalmente tales responsabilidades a SERVIR. También reserva un cupo de puestos directivos, cuya definición queda supeditada al arbitrio de la autoridad de la entidad, para ser contratados de manera directa, toda vez que el postulante se ajuste al perfil del puesto (Corrales Angulo 2014a, 2014b).

En la etapa de transición hacia el nuevo régimen, las entidades podrían nominar en cargos directivos a miembros del CGP, a graduados de la ENAP y a miembros del Fondo de Apoyo Gerencial (Decreto Legislativo 25.650) o del escalafón de Personal Altamente Calificado (Ley 29.806). Una vez sustanciada la etapa de implementación de la ley, todos los cargos directivos serían provistos mediante concursos (Iacoviello 2015, Corrales Angulo 2014b).

Esta nueva norma ha suscitado algunos desafíos e inquietudes sobre el futuro de la reforma. En primer lugar, la multiplicación de los directivos alcanzados por el sistema puede generar dificultades para asegurar la rigurosidad y trasparencia que caracterizaron los procesos para la selección de gerentes públicos, disipando los logros obtenidos. En segundo lugar, la estrategia de descentralizar las instancias de selección a los organismos podría redundar en mayores niveles de politización. Y, finalmente, el ánimo de sostener la estructura transversal para que supla necesidades 
emergentes durante la etapa de implantación del nuevo régimen y nutra de capacidades directivas a los gobiernos nacionales, colisiona con la intención primigenia de evitar la institucionalización de un cuerpo paralelo a la carrera (Iacoviello 2015, Cortázar Velarde 2014).

\section{UNA TRAYECTORIA DE INSTITUCIONALIZACIÓN DIVERGENTE}

En todos los casos la adopción de sistemas de alta dirección pública representa un esfuerzo por transitar de sistemas basados en la confianza política a sistemas profesionales (en sus distintas variantes de carrera o de empleo). Estos procesos de transición de sistemas politizados a sistemas meritocráticos (aplicado a nivel de segmentos jerárquicos en este caso), según Grindle (2012), atraviesan tres etapas sucesivas de construcción, deconstrucción y reconstrucción a raíz de la centralidad del patronazgo como elemento de poder y de gestión flexible. Las reformas administrativas son objeto de constantes presiones por repolitizar el sistema, limitando, erosionando o impidiendo la plena institucionalización de las burocracias profesionales. La instauración del mérito a nivel de los puestos ejecutivos es aún más resistida por tratarse de la franja de cargos más apreciada políticamente y por ser considerada tradicionalmente como patrimonio del vencedor (Llano 2016).

Las resistencias a la implementación efectiva de sistemas de alta dirección pública en la región, están ancladas en razones relacionadas al control de la política pública, a partir de la desconfianza de los líderes del Ejecutivo a un cuerpo de alta gerencia que sienten como poco confiable y con mucho poder (frente a su antigua red de designados de confianza personal o política), hasta aquellas vinculadas a la pérdida de recursos para el partido o coalición de gobierno (recursos financieros, como forma de recompensa a la militancia, o como recurso del Ejecutivo para gestionar una coalición de gobierno) (Kopecky, Mair y Spirova 2012).

Siguiendo el enfoque citado, se advierte que Perú y Chile han logrado institucionalizar, extender y legitimar paulatinamente sus respectivos sistemas de alta gerencia pública. Ambas reformas han sufrido embates políticos en etapa de transiciones gubernamentales, pero esas crisis han sido superadas a través de la introducción de ajustes al sistema, principalmente en el caso chileno, propiciando una trayectoria acumulativa y ascendente de modernización. En cambio, los sistemas de alta dirección en Argentina y México han tendido a desinstitucionalizarse, sin atravesar las etapas de reconstrucción. Las presiones políticas, en estos casos, han contribuido a erosionar y desnaturalizar las reformas. Los altos niveles de 
discrecionalidad imperante distorsionaron los sistemas formales.

En la totalidad de los casos analizados persistieron las presiones por reestablecer el patronazgo y tendieron a expresarse de manera similar, aunque solo algunas democracias lograron instaurar barreras para limitar la captura partidista. La politización se intensificó en períodos de recambio gubernamental, principalmente de distinto signo político. En estos contextos aumentaron las nominaciones transitorias o excepcionales, la declaración de concursos desiertos o su veto, las desvinculaciones arbitrarias o voluntarias, entre otras prácticas. Pero en los casos peruano y chileno el sistema volvió a encaminarse mediante la adopción de pequeños arreglos hasta encauzar nuevamente la reforma, mientras que en los casos argentino y mexicano el patronazgo se expandió. En estos países prosperaron los esfuerzos por ampliar el margen de discrecionalidad, sea bajando la línea divisoria entre política y administración o sea transformando a las nominaciones transitorias en regla, entre otras prácticas.

Estos procesos de implantación de los sistemas de alta dirección han repercutido en las posibilidades de ampliación del proceso modernizador. La profesionalización del segmento directivo, tanto en Perú como en Chile, ha favorecido una suerte de efecto contagio hacia el resto del aparato administrativo. La focalización de los esfuerzos reformistas en una franja de cargos de responsabilidad contribuyó a la posterior propagación de la profesionalización hacia otros niveles de la burocracia. Opuestamente, el deterioro de los sistemas de alta dirección ha ido acompañado de una sistemática marginación de la burocracia profesional en Argentina y de una falta de modernización a nivel de las restantes esferas administrativas en México.

\section{EXPLORANDO LOS FACTORES ESTRUCTURALES ASOCIADOS A LOS DIFERENTES ITINERARIOS DE REFORMA}

En primer lugar es necesario diferenciar entre los factores estructurales que juegan a favor o en contra de la institucionalización de un sistema de mérito para el conjunto del servicio civil, y aquellos que refieren únicamente a la institucionalización de un sistema de alta dirección pública. Ambos procesos apuntan en el sentido de la despolitización del servicio civil, pero no es verificable un desarrollo lineal entre ellos. Particularmente Brasil, pero también Uruguay, son sistemas de servicio civil con niveles de meritocracia altos en la región, que no han constituido sistemas de alta dirección pública asimilables a los cuatro casos de estudio. 
En consecuencia, si bien no deja ser relevante analizar toda una frondosa y valiosa literatura que analiza los factores condicionantes que contribuyen a explicar los avances, obstáculos y eventuales retrocesos del sistema de mérito en la burocracia en general, el análisis específico de los desempeños de los sistemas de alta dirección en los cuatro casos de estudio, merece una consideración particular.

Algunos trabajos han distinguido entre los factores que condicionan el cambio en las políticas públicas, y aquellos que explican su institucionalización, es decir, que garantizan su sostenibilidad en el tiempo (Mahoney 2013). En estos últimos se centrará este apartado.

A partir de los clásicos estudios sobre el presidencialismo en América Latina (Shugart y Carey 1992, Mainwaring y Shugart 2002), académicos de la región han trabajado en una distinción entre aquellos regímenes presidenciales de corte más pluralistas, que tienden a buscar acuerdos cooperativos para sus políticas públicas, y otros más plebiscitarios, de corte más decisionista (Lanzaro 2001). Las democracias con presidencialismos que desarrollan estilos más pluralistas, tendrían más posibilidades de instrumentar políticas públicas con más chances de ser sostenidas en el tiempo, en la medida que surgen de acuerdos intertemporales entre los actores más relevantes del sistema político, disfrutando de una mayor legitimidad política y social (Tomassi et al. 2006).

Existe un conjunto de variables institucionales que favorecen o entorpecen estilos más colaborativos de gestión política, aunque es difícil establecer vínculos directos entre estas variables. Dentro del conjunto de variables que suelen ser tenidas en cuenta se destaca el grado de institucionalización del sistema de partidos, y los poderes constitucionales y partidarios del Presidente.

Un sistema de partidos institucionalizado, según Mainwaring y Scully (1995), es un sistema con prácticas estables y bien conocidas, y universalmente aceptadas. En esos sistemas, los actores (ciudadanos, políticos partidarios) desarrollan expectativas y comportamientos basados en que sus premisas permanecerán en el futuro. Cuatro serían las dimensiones que permiten identificar el grado de institucionalización de un sistema de partidos: 1) la estabilidad en los patrones de competencia entre partidos; 2) el enraizamiento de los partidos en la sociedad; 3) la legitimidad de los partidos; y 4) el nivel de organización partidaria.

Más allá de los cuestionamientos que el concepto ha recibido, hay cierto consenso en la afirmación de los autores de que en un sistema 
de partidos débilmente institucionalizado, hay más chances de que las políticas públicas sean más erráticas, menos legítimas y que predominen las prácticas patrimonialistas en la administración pública (Mainwaring y Scully. 1995). Los autores advierten acerca de los problemas que los sistemas de partidos incipientes tienen para la calidad de las democracias latinaomericanas. Cambios electorales bruscos y recurrentes, asociados a síntomas que reflejan la ausencia de partidos fácilmente identificables ideológicamente para sus ciudadanos, no favorecen la rendición de cuentas de los gobernantes (Manin, Przeworski y Stokes. 1999), y las elites políticas no encuentran incentivos para realizar acuerdos intertemporales entre ellas (Tommassi et al. 2006). Por otro lado, los estudios de caso en América Latina han demostrado que el multipartidismo moderado en casos de gobiernos de coalición, así como una polarización ideológica moderada, son indicadores positivos respecto a la calidad democrática (Torcal 2015).

$\mathrm{Si}$ se repasa la literatura referente a los equilibrios de poderes entre el Ejecutivo y el Legislativo, variable que se considera fundamental para la calidad de la democracia, los análisis se centran en la naturaleza de los poderes constitucionales del Presidente, y en el nivel de apoyo partidista al Presidente en el ámbito Legislativo, es decir, los poderes derivados del partido (Mainwaring y Shugart 2002).

Dentro de los primeros, se distinguen las facultades del Presidente en el proceso legislativo (vetar proyectos de ley, promulgar leyes por decreto, derecho exclusivo a presentar proyectos de ley en determinadas materias, entre otros), y sus prerrogativas para formar el gabinete (sin que el Parlamento pueda censurarlos y pedirles la renuncia) y designar otras autoridades políticas. Dentro de los segundos, hay algunos asociados a factores institucionales (legislación electoral y estructura del sistema de partidos) y otros coyunturales, como el resultado de las elecciones (la participación del partido o coalición dentro del Congreso y el grado de disciplina partidaria) y la capacidad de liderazgo presidencial (por ejemplo, si es jefe de su partido) (Mainwaring y Shugart 2002).

Ambos tipos de poder (legislativo y de partido) deben ser considerados en conjunto, ya que un Presidente con fuertes poderes constitucionales puede llegar a ser débil si cuenta con un sistema de partidos altamente fragmentado y una base poco confiable de apoyos parlamentarios, tal como lo evidencia la experiencia brasileńa reciente. 
Tabla 2: Modelo de cambio institucional/elementos condicionantes de las reformas directivas

Grado de institucionalización de los sistemas de partidos

Poderes constitucionales del Presidente
Nivel de implantación de los sistemas de alta dirección pública

Poderes partidistas del Presidente

Fuente: Elaboración propia.

Si se analizan los cuatro casos de estudio y se intenta vincular la mayor institucionalización de los sistemas de alta dirección pública en los casos de Chile y Perú, y el más bajo desempeño en el caso de México y Argentina, no se aprecia siempre una correspondencia lineal y sencilla con estos factores institucionales señalados por la literatura. Probablemente los casos que evidencian un vínculo más nítido son los de Argentina y Chile.

En el caso argentino, donde el sistema de alta dirección pública no ha podido institucionalizarse, podría vincularse a un progresivo proceso de desinstitucionalización y fragmentación del sistema de partidos (vinculado en parte al ascenso de los partidos provinciales y aumento del clientelismo) (Scherlis 2008, Lupu 2015, Levitsky 2003). El sistema de partidos argentino no se ha caracterizado tradicionalmente por una polarización alta (Alcántara 2004), y este factor que no ha variado sustancialmente en los últimos ańos de administración kirchnerista (Tagina 2013). No obstante, el estilo contencioso de hacer política de sus elites partidarias ha obstaculizado alianzas y gobiernos de coalición.

Al mismo tiempo, en el período analizado, los poderes constitucionales del Presidente se han visto sustancialmente incrementados, al punto de tener las características propias de un hiperpresidencialismo (Novaro 2001, Bonvechhi y Scartascini 2014). Otro tanto ha sucedido con los poderes derivados del apoyo legislativo a su partido, en la medida que desde el ańo 2003 el Frente para la Victoria y sus aliados en el Justicialismo consolidaron una tendencia hacia un sistema de partido predominante, bajo el liderazgo de las fuertes figuras presidenciales de los Kirchner.

Estos rasgos institucionales contribuyeron a plasmar una democracia delegativa y un estilo de liderazgo presidencial de corte fuertemente 
plebiscitario. En estos esquemas, los liderazgos presidenciales son carismáticos, y apelan a un decisionismo imperativo, que rodea a los partidos políticos y coloniza las estructuras administrativas del Estado. Evidentemente no son esquemas que se recuesten en sistemas de profesionalización de la función pública.

En el caso de Chile, donde el Sistema de Alta Dirección Pública ha ido dando pasos concretos hacia su institucionalización (superando gradualmente problemas de alta rotación asociados a cambios de gobierno), también podría vincularse a las características de su sistema de partidos. El sistema de partidos chileno es considerado tradicionalmente como uno de los más institucionalizados de la región, a pesar de que en opinión de Altman y Luna (2015), la estabilidad electoral creciente viene acompañada de un progresivo desarraigo de los partidos entre los votantes.

En cuanto a los poderes presidenciales, si bien el Presidente chileno es de los más fuertes de la región (llegándose a calificar como de presidencialismo exagerad"), paradójicamente estos han mostrado una clara tendencia hacia la moderación, con estilos de política claramente cooperativos y pluralistas (Siabelis 2002). Esto se debe en parte a que el Presidente chileno tiene fuertes poderes de establecimiento de agenda, pero no tiene facultades (como en Argentina) de cambiar unilateralmente el statu quo por medio de decretos sin aprobación previa del Congreso y sin restricción en las materias de ley sobre las que puede aplicar (Aninat 2006).

Al mismo tiempo, el Congreso chileno bicameral, con quórums especiales y uso extensivo de comisiones, sumado a un Tribunal Constitucional independiente, refuerzan su posición frente al Presidente. En cuanto al nivel de apoyo partidario del Presidente, el hecho de que el sistema electoral lleva a que los partidos se organicen en dos grandes bloques producto de coaliciones estables y disciplinadas lleva a que el Presidente gobierne con una coalición que ronda entre el 40\% y 60\% de los escaños en cada cámara. Sumado al elevado costo que pagaría un partido por abandonar unilateralmente la coalición (hay un umbral muy elevado para obtener representación parlamentaria), induce a un comportamiento muy disciplinado de los parlamentarios que integran los bloques de coalición. El Presidente goza entonces de un poder nada despreciable frente al Congreso, pero debe negociar y llegar a acuerdos para reformas sustantivas que impliquen quórums calificados (Carey 2002).

En Perú en cambio, sistema de partidos colapsó a partir de 1992, en el sentido de que al compás de la consolidación del fujimorismo no solo se 
produjo una aguda crisis que desencadenó cambios en el sistema de competencia partidaria, sino la desaparición de todos los actores partidarios tradicionales (Tanaka 2015). Este rasgo institucional se complementa con el de un presidencialismo atenuado, no tanto por sus poderes constitucionales, que son amplios (Patriau 2014), sino porque estos aparecen combinados con poderes partidarios débiles, debido al tamaño moderado que suele tener la bancada del Presidente en el Congreso (García Marín 2015). Estas mismas características han llevado a los presidentes a hacer un uso abusivo de sus poderes de decreto como vía de generación legislativa. Tal como afirma Duque (2015), un sistema de partidos débilmente institucionalizado, con bajas disciplinas internas y fuerte autonomía de los parlamentarios, generan dinámicas clientelares y de confrontación con el Ejecutivo.

Como es notorio, estos factores institucionales no son los más adecuados para realizar acuerdos cooperativos de largo aliento, y en consecuencia no contribuyen a explicar la progresiva institucionalización de la alta dirección pública peruana. Para ello sería necesario acudir al análisis de otros factores ajenos al sistema de partidos y poderes presidenciales. Una de las pistas que habría que explorar es la existencia de un fuerte núcleo de tecnócratas en áreas estratégicas de gobierno, que gozan de cierta estabilidad y autonomía respecto a la política partidaria (Dargent 2014).

En el caso de México, se trata de un sistema político que ha transitado desde una situación de institucionalización con hegemonía partidaria (hasta 1997), hacia una institucionalización en un contexto de una competencia equilibrada entre partidos, con un grado de fragmentación moderada.

A diferencia de la mayoría de países latinoamericanos que al salir de las dictaduras mantuvieron o buscaron expandir los poderes legislativos de sus presidentes, México ha buscado restringirlos. El Presidente mexicano cuenta con poderes legislativos débiles, ya que a diferencia de la mayoría de sus pares latinoamericanos, no dispone de facultades legislativas que hagan avanzar su agenda y cambiar el statu quo. Con respecto a los poderes partidarios, si se los compara con los de la época priista, los jefes de Estado ya no son necesariamente jefes de su partido, y sus partidos no cuentan con mayorías parlamentarias, careciendo de votos para aprobar sus iniciativas legislativas por sí solos (Amparo Casar 2013).

En primera instancia, los factores institucionales analizados en el caso mexicano, no parecen ser determinantes para explicar la baja institucionalización de las reformas en la alta dirección pública. Al igual 
que en el caso peruano, es necesario apelar a otros factores. Debería analizarse por ejemplo, en este contexto de relativa debilidad legislativa presidencial, la permanente apelación a la utilización de amplios poderes de patronazgo político del Presidente, como moneda de cambio para comprar las voluntades de las dirigencias partidarias, a los efectos de promover cuestiones de agenda de gobierno.

Los factores institucionales nunca han sido predictores infalibles de rendimientos democráticos y sostenibilidad de políticas, pero sí brindan marcos generales de referencia a partir del cual se pueden estudiar reformas estructurales. Sin embargo, para avanzar en la comprensión de estos fenómenos, como los de la sostenibilidad de las reformas, es necesario profundizar en los estudios de caso nacionales, incorporando más variables contextuales y factores de agencia relativos a las ideologías y proyectos políticos de los sucesivos gobiernos.

\section{COMENTARIOS FINALES}

La institucionalización de los sistemas de alta dirección pública en América Latina ha seguido itinerarios muy asimétricos. Mientras que Chile y Perú han seguido una trayectoria acumulativa en la que el cambio institucional se ha ido consolidando y propagando gradualmente, los países que optaron por seguir estrategias de modernización administrativa globales, como Argentina y México, no lograron implantar sus sistemas directivos plenamente. En estos últimos casos, las incesantes presiones por repolitizar las preciadas posiciones jerárquicas contribuyeron a deconstruir las reformas.

En todos los casos los sistemas de alta dirección se vieron expuestos a crisis, desatadas principalmente en los períodos de transiciones políticas. En estas etapas, el componente discrecional se reinstaló en detrimento del mérito, aflorando prácticas que buscaban eludir el sistema, como las remociones, las nominaciones transitorias, el veto a los concursos, entre otras. Pero solo Chile y Perú lograron reestabilizar el proceso de implementación de sus sistemas, en cambio, en Argentina y México los recambios gubernamentales profundizaron la erosión de sus mecanismos de gestión de los altos directivos.

En el proceso de ascendente institucionalización, los sistemas directivo chileno y peruano se han ido legitimando y tornando más confiables. Esta tendencia se refleja en la extensión del sistema hacia áreas no previstas originalmente así como en el incremento de las postulaciones. Opuestamente, en Argentina y México el deterioro de la reforma ha ido 
acompañado de una creciente pérdida de credibilidad en el sistema. En los remanentes procesos de selección que se aplican, prevalece la percepción generalizada de que el sistema es objeto de manipulación, desalentando a los eventuales aspirantes.

Estas trayectorias disímiles indefectiblemente generan interrogantes sobre los condicionantes de las reformas. A partir de un análisis exploratorio sobre la incidencia de las variables político-estructurales en los cambios administrativos, no se ha logrado identificar un entramado institucional específico que suscite una lógica de construcción (deconstrucción) incremental de la reforma que conduzca a la institucionalización (desinstitucionalización) de los sistemas de alta dirección pública en la región. Estos hallazgos incitan a ahondar en el estudio de los factores asociados al sustento de los procesos de modernización.

Esto abre una agenda de investigación a futuro. Es necesario conocer con mayor profundidad los motivos por los que los procesos de profesionalización del alto servicio civil (aun logrando institucionalizarse, como en Chile y Perú), son cíclicamente resistidos en el presidencialismo latinoamericano. Como lo ha señalado Grindle (2012), la profesionalización del servicio civil en la región, se expresa en una tensión constante entre impulsos reformistas y retrocesos vinculados a prácticas de patronazgo político. Se conocen aún muy poco las razones por las que el patronazgo político es funcional a los gobiernos de turno. Avanzar en esta materia es indispensable para reflexionar acerca de las variables (de estructura o de agencia) que intervienen en los procesos de (des)institucionalización de los sistemas de alta dirección pública. 


\section{REFERENCIAS}

Acuña, C. (2008). La Política de la Modernización Estatal: Notas Comparando la Experiencia Europea con la Latinoamericana (con Foco en Argentina). Revista CLAD. Reforma y Democracia, 40, 103124.

Alcántara Sáez, M. (2004) ¿Instituciones o Máquinas Ideológicas? Origen, Programa y Organización de los Partidos Políticos Latinoamericanos. Barcelona: ICPS.

Altman, D. y Luna, J. P. (2015). ¿Partidos Hidropónicos en un Sistema de Partidos Muy Institucionalizado? El caso de Chile. En Torcal, M. (Ed.), Sistema de Partidos en América Latina. Causas y Consecuencias de su Equilibrio Inestable. Barcelona: Anthropos Editorial; Santa Fe: Ediciones Universidad Nacional del Litoral.

Amparo Casar, M. (2013). Fifteen Years of Minority Governments in Mexico (1997-2012). Politica y Gobierno, 20 (2), 219-263.

Aninat, C. (2006). Balance de Poderes Legislativos en Chile. ¿Presidencialismo Exagerado o base de un Sistema Político Cooperativo? Política, 47, 127-148.

Arellano, D. (2008). La Implementación de un Servicio Civil Meritocrático: ¿Un Asunto Técnico? El Caso de México. En Longo, F. y Ramió, C. (Eds.), La Profesionalización del Empleo Público en América Latina. Barcelona: Fundació CIDOB.

\section{(2013). ¿Burocracia Profesional Individualista o} Espíritu de Cuerpo? Las Contradicciones del Servicio Civil Mexicano. Andamios. Revista de Investigación Social, 10 (21), 13-37.

Aristegui Noticias (2012). Desempolva PRI Iniciativa para Despedir 3,937 Funcionarios Públicos. Disponible en http://aristeguinoticias. $\mathrm{com} / 2111 / \mathrm{mexico} /$ resucita-pri-iniciativa-para-despedir-a-3-mil-937funcionarios/ [04-12-2017].

Bonvecchi, A. y Scartascini, C. (2014). The Organization of the Executive Bñranch in Latin America: What We Know and What We Need to Know. Latin American Politics and Society, 56 (1), 144-165. 
Cámara de Diputados de Chile (CDC). (2015). Informe de la Comisión de Hacienda Proyecto de Ley Perfeccionamiento Sistema de Alta Dirección Pública y Fortalecimiento de la Dirección Nacional del Servicio Civil. Boletín No 10.164-05. Disponible en www.camara.cl [04-12-2017].

Carey, J. (2002). Parties, Coalitions, and the Chilean Congress in the 1990s. En Morgenstern, S. y Nacif, B. (Eds.), Legislative Politics in Latin America. Cambridge: Cambridge University Press.

Corrales Angulo, A. (2010). Diseño e implementación del Cuerpo de Gerentes Públicos en Perú. Ponencia presentada en el XV Congreso Internacional del CLAD sobre la Reforma del Estado y la Administración Pública, 9-12 de noviembre, Santo Domingo, República Dominicana,

- (2014a). Balance de la Experiencia del Cuerpo de Gerentes Púbicos de Perú. En XIX Congreso del CLAD sobre la Reforma del Estado y de la Administración Pública,11-14 de noviembre, Quito, Ecuador.

. (2014b). La Nueva Ley del Servicio Civil y el Desafío de los Directivos en la Reforma del Servicio Civil Peruano. En XIX Congreso del CLAD sobre la Reforma del Estado y de la Administración Pública, 11-14 de noviembre, Quito, Ecuador.

Corrales Angulo, A. y Martín, A. (2012). Aportes del Cuerpo de Gerentes Públicos a la Reforma del Servicio Civil en el Perú. Ponencia presentada en el XVII Congreso Internacional del CLAD sobre la Reforma del Estado y de la Administración Pública, 30 de octubre al 2 de noviembre, Cartagena, Colombia.

Cortázar Velarde, J. C. (2011). Aprendiendo a partir de la Reforma del Servicio Civil en Chile. Algunas Lecciones de Interés para Países Latinoamericanos. Revista del CLAD. Reforma y Democracia, 49, 99122.

Servicio Civil. Washington: BID.

(2014). Perú: Gradualidad Innovación en la Reforma del

Cortázar Velarde, J. C., Fuenzalida, J. y Lafuente, M. (2016). Sistemas de Mérito para la Selección de Directivos Públicos. ¿Mejor Desempeño del Estado? Washington: BID. 
Cortázar Velarde, J. C., Lafuente, M. y Schuster, C. (2014). Estrategias para Avanzar en la Modernización del Servicio Civil en América Latina. En Cortázar Velarde, J. C., Lafuente, M. y Sanginés, M. (Eds.), Al Servicio del Ciudadano. Una Década de Reformas del Servicio Civil en América Latina (2004-13). Washington: BID.

Coutinho, M. E. (2016). Directivos públicos-Funcionarios Políticos. Una Relación Débilmente Institucionalizada. En CIPPEC y ASAP (Eds.), GPS del Estado. Buenos Aires: CIPPEC, ASAP.

Dargent, E. (2014). Technocracy and Democracy in Latin America. The Experts Running Government. Cambridge: Cambridge University Press.

Duque Daza, J. (2015). ¿Presidentes Legislando? Las Facultades Legislativas en el Presidencialismo Colombiano, 1991-2014. Revista Estudios Sociojurídicos, 17 (1), 79-123.

Dirección Nacional de Servicio Civil (DNSC) (2016). Sistema de Alta Dirección Pública. Disponible en http://www.serviciocivil.gob.cl/ [0412-2017]-

Dussauge Laguna, M. (2011). The Challenges of Implementing MeritBased Personnel Policies in Latin America: Mexico's Civil Service Reform Experience. Journal of Comparative Policy Analysis: Research and Practice, 13 (1), 51-73.

Egaña Baraona, R. (2014). Sin título. En Dirección Nacional de Servicio Civil, Seminario Internacional de Alta Dirección Pública 2014: Nuevos Desafios y Reformas Pendientes. Santiago: DNSC.

(2016). El Servicio Civil de Chile: Modelo de Profesionalización del Empleo Público. DNSC. Ponencia presentada en el Ministerio de Modernización, 30 de mayo, Buenos Aires, Argentina.

El Economista (2013). Funcionarios heredados por el PAN, nudo al gobierno de EPN. Disponible en http://eleconomista.com.mx/ sociedad/2013/02/22/funcionarios-heredados-pan-nudo-gobiernoepn [04-12-2017]. 
García Marín, I. (2015). Relaciones entre el Ejecutivo y el Legislativo y el Sistema de Partidos: Perú 2006-2011. Ponencia presentada en XII Congreso de AECPA, 13-15 de julio, San Sebastián, España.

González Bustamante, B., Olivares, A., Abarca, P. y Molina, E. (2016). Servicio Civil en Chile, análisis de los directivos de primer nivel jerárquico (2003-2013). Revista de Administraçao Pública, 50 (1), 5979.

Grindle, M. (2012). Job for the Boys. Patronage and the State in Comparative Perspective. Cambridge: Harvard University Press.

Halligan, J. (2003). Leadership and the Senior Service from a Comparative Perspective. En Peters, G. y Pierre, J. (Eds.), Handbook of Public Administration. Londres: Sage.

Hood, C. (2000). Relationships between Ministers/Politicians and Public Servants: Public Service Bargains Old and New. En Peters, G. y Savoie, D. J., (Eds.,) Governance in the Twenty-First Century: Revitalizing the Public Service. Kingston: Mc-Gill-Queen's University Press.

Hood, C. y Lodge, M. (2006). The Politics of Public Service Bargains: Reward, Competency, Loyalty-and Blame. Oxford: Oxford University Press.

Iacoviello, M. (2009). Diagnóstico Institucional del Sistema de Servicio Civil de Chile. Evaluación Final del Programa de Fortalecimiento de la Dirección Nacional de Servicio Civil. Santiago: BID, Gobierno de Chile.

. (2010). La Calidad Institucional del servicio Civil Chileno: Evolución, Avances y Desafíos Pendientes. Ponencia presentada en el XV Congreso del CLAD sobre Administración Pública y Reforma del Estado, 30 de octubre al 2 de noviembre, Santo Domingo, República Dominicana.

BID. . (2011). Diagnóstico: Servicio Civil de Perú. Washington: . (2015). Diagnóstico Institucional del Servicio Civil en América Latina: Perú. Washington: BID.

Iacoviello, M. y Llano, M. (2016). Política y Burocracia. Apuntes de una Relación (Históricamente) Difícil. En CIPPEC y ASAP (Eds.), GPS 
del Estado. Buenos Aires: CIPPEC, ASAP.

(2017). Confianza Mata Mérito: El Impacto de la Concentración de Poder Presidencial en la Gestión de Recursos Humanos en el Estado Argentino. Temas y Debates, 33, 91-105.

Iacoviello, M., Llano, M. y Strazza, L. (2012). Fortalecimiento de la Función Directiva Pública: Exploración a partir de una Selección de Experiencias Latinoamericanas y Anglosajonas. Revista del CLAD. Reforma y Democracia, 52, 45-82.

Iacoviello, M., Rodríguez Gustá, A. L. y Cruz Orozco, I. (2006). Caso México. En Echebarría, K. (Ed.), Informe sobre la Situación del Servicio Civil en Latinoamérica. Washington: BID.

Iacoviello, M. y Strazza, L. (2014). Diagnóstico del Servicio Civil en América Latina. En Cortázar Velarde, J. C., Lafuente, M. y Sanginés, M. (Eds.), Al Servicio del Ciudadano. Una Década de Reformas del Servicio Civil en América Latina (2004-13). Washington: BID.

Iacoviello M. y Tomassi, M. (2002). Diagnóstico Institucional de Sistemas de Servicio Civil. Caso Argentino. Washington: BID.

Iacoviello, M., Zuvanic, L. y Tommasi, M. (2003). Politización, Estrategia y Cultura Burocrática: Áreas de Abordaje para la Reforma del Servicio Civil en Argentina. En VIII Congreso Internacional del CLAD sobre la Reforma del Estado y de la Administración Pública, 28-31 de octubre, Ciudad de Panamá, Panamá.

Inostroza, J., Morales Casetti, M. y Fuenzalida, J. (2011). Modernización del Sistema de Elección de Directivos del Estado: Un Proceso Inconcluso. En Walter, J. y Pando, D. (Eds.), Planificación Estratégica: Nuevos desafíos y enfoques en el Ámbito Público. Buenos Aires: SAAP.

Kopecký, P., Mair, P. y Spirova, M. (2012). Party Patronage and Party Government in European Democracies. Oxford: Oxford University Press.

Kuperus, Hy Rode, A. (2008). Top Public Managers in Europe. Management and Working Conditions of Senior Civil Servants in the European Union Members States. Maastricht: EIPA.

Lafuente, M., Manning, N. y Watkins, J. (2012). International Experiences with Senior Executive Service Cadres. World Bank's Global 
Expert Team on Public Sector Performance (PSP GET). Disponible en http://siteresources.worldbank.org/EXTGOVANTICORR/ Resources/3035863-1285601351606/GET_Note_Recently_Asked_ Questions_Senior_Executive_Services.pdf [04-12-2017].

Lah, T. J. y Perry, J. L. (2008). The Diffusion of the Civil Service Reform Act of 1978 in OECD Countries: A Tale of Two Paths to Reform. Review of Public Personnel Administration, 28 (3), 282-299.

Lanzaro, J. L. (2001). Tipos de Presidencialismo y Coaliciones Politicas en América Latina. Buenos Aires: Consejo Latinoamericano de Ciencias Sociales.

Levitsky, S. (2003). Transforming Labor-Based Parties in Latin America: Argentine Peronism in Comparative Perspective. Cambridge: Cambridge University Press.

Longo, F. (2013). Diez Años de Alta Dirección Pública en Chile. Ponencia presentada en XVIII Congreso Internacional del CLAD sobre la Reforma del Estado y de la Administración Pública, 29 de octubre al 1 de noviembre, Montevideo, Uruguay.

Lupu, N. (2015). Nacionalización e Institucionalización de Partidos en la Argentina del Siglo XX. En Torcal, M. (Ed.) Sistemas de partidos en América Latina. Barcelona: Anthropos; Santa Fe: Ediciones Universidad Nacional del Litoral.

Llano, M. (2014). Diagnóstico Institucional del Servicio Civil en América Latina: Chile. Washington: BID.

(2015). Revisando la presunta Naturaleza Paradigmática de la Nueva Gerencia Pública y su Repercusión en Iberoamérica. $D A A P G E, 24,67-100$.

. (2016). Burocracia Pública y Sistema Político en América Latina. Factores Asociados a la Politización de los Sistemas de Gestión de Empleo Público en la Región. Tesis doctoral (Gobierno y Administración Pública), Instituto Universitario de Investigación Ortega y Gasset, adscrito a la Universidad Complutense de Madrid, Madrid, España.

Mahoney, J. (2013). Militarization without Bureaucratization in Central America. En Centeno, M. y Ferraro, A. (Eds.), State and Nation-Making in Latin America and Spain: Republics of the Possible. Cambridge: Cambridge University Press. 
Mainwaring, S. y T. Scully (Eds.). (1995) Building Democratic Institutions Party Systems in Latin America. Stanford: Stanford University Press.

Mainwaring, S. y Shugart, M. S. (2002). Presidencialismo y Democracia en América Latina. Buenos Aires: Paidós.

Mainwaring, S. y Torcal, M. (2005). La Institucionalización de los Sistemas de Partidos y la Teoría del Sistema Partidista Después de la Tercera Ola Democratizadora. América Latina Hoy, 41, 141-173.

Manning, N., Przeworski, A. y Stokes, S. (1997). Democracy, Accountability and Representation. Cambridge: Cambridge University Press.

Martínez Puón, R. (2008). Cinco mitos sobre el servicio profesional de carrera en México. Convergencia, 48, 203-221.

. (2009). La Nueva Fisonomía del Servicio Profesional de Carrera en México. Revista del CLAD. Reforma y Democracia, 43, 177-206.

Minsky, R. (1997). El Cuerpo de Administradores Gubernamentales y su Inserción en la Administración Pública. Aportes para el Estado y la Administración Gubernamental, 9.

Negri, S. (2000). La Función Pública en la República Argentina: Impresiones de una Historia Reciente de avances y retrocesos: El Caso del Cuerpo de Administradores Gubernamentales. Ponencia presentada en el V Congreso Internacional del CLAD sobre la Reforma del Estado y de la Administración Pública, 24-27 de octubre, Santo Domingo, República Dominicana.

(2005). Ser o no Ser Administrador Gubernamental. Ponencia presentada en el X Congreso Internacional del CLAD sobre la Reforma del Estado y de la Administración Pública, 18-21 de octubre, Santiago, Chile.

Novaro, M. (2001). Presidentes, Equilibrios Institucionales y Coaliciones de Gobierno en Argentina (1989-2000). En Lanzaro, J. L. (2001), Tipos de Presidencialismo y Coaliciones Politicas en América Latina. Buenos Aires: Consejo Latinoamericano de Ciencias Sociales.

Organización para la Cooperación y Desarrollo Económico (OCDE). (2011). Hacia una Gestión Pública Más Efectiva Más Efectiva y Dinámica 
en México. París: OCDE.

Oficina Nacional de Empleo Público (ONEP). (2007). Inserción Laboraly Desarrollo de Carrera de la Trabajadora Estatal. El caso SINAPA, CABA. Buenos Aires: ONEP.

Oszlak, O. (1983). Burocracia Estatal: Cementerio de Proyectos Políticos. Clarin, 24 de enero.

(1994). Los A.G: La Creación de un Cuerpo Gerencial de Élite en el Sector Público Argentino. Revista Aportes para el Estado y la Administración Gubernamental. 1 (1), 82-107.

Pardo, M. C. (2015). La Modernización Administrativa del Gobierno de Felipe Calderón: entre la Austeridad y la Reforma. Foro Internacional, LV (1), 83-115.

Patriau, E. (2014). El Congreso Peruano: Políticas Públicas e Influencia Informal sobre la Burocracia. Perfiles Latinoamericanos, 22(43), 103126.

Peftouloglou, B. (2015). Los Procesos de Selección de Directivos Públicos en el Servicio Civil Chileno. Ponencia presentada en el XX Congreso Internacional del CLAD sobre la Reforma del Estado y de la Administración Pública, 10-13 de noviembre, Lima, Perú.

Piemonte, V. (2005). El Cuerpo de Administradores Gubernamentales: la Piedra Fundamental. Ponencia presentada en el X Congreso Internacional del CLAD sobre la Reforma del Estado y de la Administración Pública, 18-21 de octubre, Santiago, Chile.

Pulido, N. (2005). El Cuerpo de Administradores Gubernamentales: La Perspectiva Académica. Ponencia presentada en el X Congreso Internacional del CLAD sobre la Reforma del Estado y de la Administración Pública, 18-21 de octubre, Santiago, Chile.

Ramos, C. y Scrollini, F. (2013). Los Nuevos Acuerdos entre Políticos y Servidores Públicos en la Alta Dirección Pública en Chile y Uruguay. Revista Uruguaya de Ciencia Política, 22 (1), 11-36.

Rivas Tovar, L., Trujillo Flores, M., Lámbarry Vilchis, F., Chávez, A. y Chávez Espejel, J. (2013). Diagnóstico del Sistema Profesional de Carrera y Certificación de Competencias Gerenciales de los Servidores 
Públicos en México. Estudios Gerenciales, 29, 428-438.

Rouban, L. (2007). Political-Administrative Relations. En Raadschelders, J. C., Toonen, T. A. J. y Van der Meer, F. M. (Eds), The Civil Service in the 21st Century. Londres: Palgrave Macmillan.

Salas, E. (2003). Un Balance Provisional del Sistema Nacional de la Profesión Administrativa a Doce Años de su Vigencia. Ponencia presentada en el Segundo Congreso Argentino de Administración Pública. Sociedad, Estado y Administración, 27-29 de noviembre, Córdoba, Argentina.

. (2005). Algunas Experiencias y Enseñanzas Derivadas del Proceso de Rediseño y Gestión del Servicio Civil en Argentina. Ponencia presentada en el Foro Iberoamericano: Revitalización de la Administración Pública. Estrategias para la Implantación de la Carta Iberoamericana de la Función Pública, 5-6 de mayo, Ciudad de México, México.

Salas, E. y Wegman, M. (2016). Para el Servicio Civil que Merece un País en Serio: Hacia la Consolidación del Derecho de Igualdad de Todo Ciudadano a Ingresar a la Administración Publica por Concursos de Méritos y Capacidades. Cuaderno de Administración Buenos Aires: AAEAP.

Sartori, G. (1980). Partidos y Sistema de Partidos. Madrid: Alianza.

Scherlis, G. (2008). Machine Politics and Democracy: The Deinstitutionalization of the Argentine Party System. Government and Opposition, 43 (4), 579-598.

Shugart, M. S. y Carey, J. M. (1992). Presidents and Assemblies: Constitutional Design and Electoral Dynamics. Cambridge: Cambridge University Press.

Siavelis, P. (2002). Exaggerated Presidentialism and Moderate Presidents: Executive-Legislative Relations in Chile. Legislative Politics in Latin America, 50, 79-113.

Silva, F. (2011). Profesionalización de la Función Pública: La Experiencia Chilena (Reforma 2003-2011). Desigualdade \& Diversidade, Dossiê Especial, 35-48.

Strazza, L. (2014). Diagnóstico Institucional del Servicio Civil en América Latina: México. Washington: BID. 
Tagina, M. L. (2013). Política y Polarización en Argentina: Un Estudio del Comportamiento de las Élites, los Partidos Políticos y la Opinión Pública. Revista de Derecho Electoral, 17, 185-212.

Tanaka, M. (2015). Agencia y Estructura, y el Colapso de los Sistemas de Partidos en los Países Andinos. En Torcal, M. (Ed.) Sistemas de partidos en América Latina. Barcelona: Antrophos; Santa Fe: Ediciones Universidad Nacional del Litoral.

Tommasi, M., Stein, E., Echebarría, K., Lora, E. and Payne, M. (2006). The Politics of Policies: Economic and Social Progress in Latin America. Washington: BID.

Torcal, M. (Ed.). (2015). Sistema de partidos en América Latina. Causas y Consecuencias de su Equilibrio Inestable. Barcelona: Anthropos Editorial; Santa Fe: Ediciones Universidad Nacional del Litoral.

Waissbluth, M. (2008). Alta Dirección Pública: Una Reforma Contracultural, Mensaje, septiembre, 390-394.

Zuvanic, L. (2016). Apuntes de una relación (Históricamente) Difícil. En CIPPEC y ASAP (Eds.), GPS del Estado. Buenos Aires: CIPPEC, ASAP.

Zuvanic, L. y Iacoviello, M. (2010). La Burocracia en América Latina. ICAP-Revista Centroamericana de Administración Pública, 58-59, 9-41.

Recibido: 02-02-2017

Aceptación de la versión final: 13-12-2017 